\title{
ton INTERNATIONAL IOURNAL OF \\ Use of an artificial mammary implant in total pelvic exenteration
}

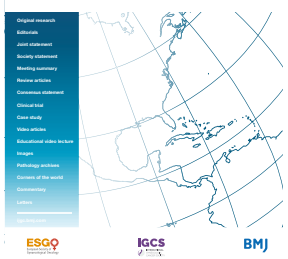

Robert Adam Farrell (D) , ${ }^{1}$ Patrick J Maguire, ${ }^{1}$ Aoife Freyne, ${ }^{1}$ Shmaila Siddiki, ${ }^{1}$ Feras Abu Saadeh ${ }^{1,2}$

${ }^{1}$ Department of Gynaecological Oncology, St. James's Hospital, Dublin, Ireland

${ }^{2}$ Trinity College Department of Obstetrics and Gynaecology, Trinity Centre for Health Sciences, St. James's Hospital, Dublin, Ireland

\section{Correspondence to} Dr Feras Abu Saadeh, Department of Gynaecological Oncology, St. James's Hospital, Dublin 8, Ireland; ferasabusaadeh@dubgyn.org

Accepted 4 January 2021 Published Online First 1 March 2021
In this video article we demonstrate the pelvic placement of an artificial mammary implant as part of total pelvic exenteration surgery. The initial steps in this procedure are inspection of the abdomen and pelvis with two port laparoscopy, and isolation of the primary tumor by circumferential incision of the vulva, perineum, and anus extending to the right levator ani. We then illustrate the opening of the abdomen through midline laparotomy, removal of the resection specimen en-bloc, and closure of the pelvic floor and perineum. We provide guidance on the selection of appropriately sized mammary implant by instillation and subsequent removal of a measured volume of sterile isotonic saline into the pelvis. Once selected, the appropriate implant (CPG 323, Mentor, USA) is delivered to the pelvis, covered by polyglactin mesh (Vicryl, Johnson and Johnson, USA), secured with surgical tacks, and finally covered with an omental J-flap mobilized from the transverse colon to decrease adhesional complications. The procedure also included systematic pelvic and paraaortic lymphadenectomy, formation of colonic urinary conduit with bilateral ureteric stent insertion, end colostomy formation, placement of two surgical drains to the pelvis, to reduce the risk of infection, and right inguino-femoral lymphadenectomy as FDG avid inguinal node was observed on preoperative PET scan.

The use of a mammary implant to occupy the pelvis following total pelvic exenteration is a feasible option using the techniques demonstrated here where other surgical approaches were unsuitable (Figure 1). Up to $40 \%$ of post-operative complications of pelvic exenteration relate to pelvic sepsis and perineal wound infections, exacerbated by fluid accumulation and

\section{INTERNATIONAL JOURNAL OF GYNECOLOGICAL CANCER}

\section{Use of an artificial mammary implant in total pelvic exenteration}

\author{
Robert A Farrell; Patrick J Maguire; Aoife Freyne; Shmaila Siddiki; Feras Abu
} Saadeh.

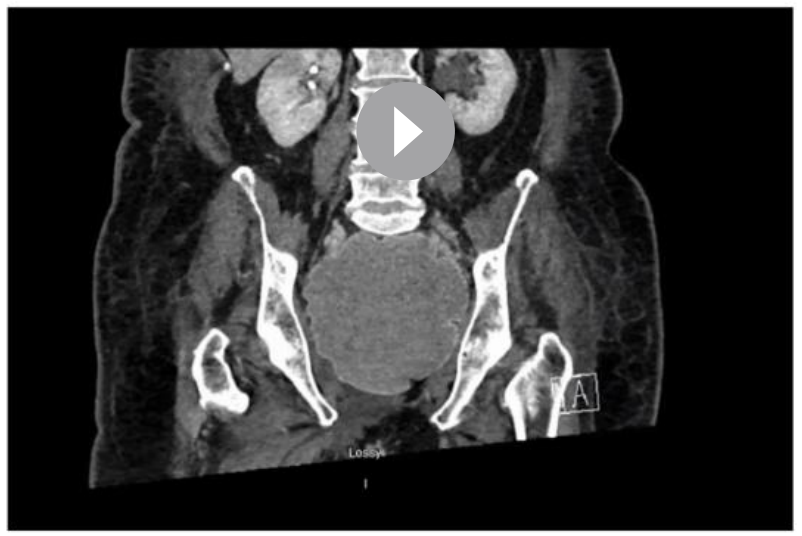
commercial re-use. See rights and permissions. Published by BMJ.

\begin{tabular}{l}
\hline To cite: Farrell RA, \\
Maguire PJ, Freyne A, \\
et al. Int J Gynecol Cancer \\
2021;31:1186-1187. \\
\hline
\end{tabular}

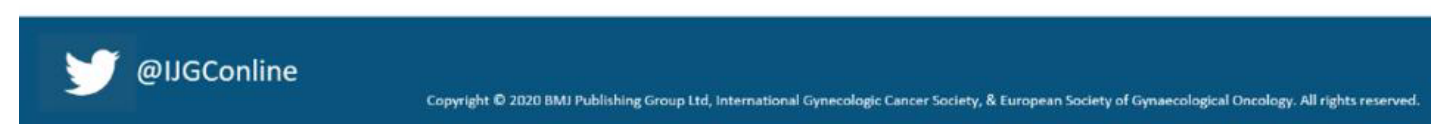

Video 1 Demonstration of sizing and placement of a pelvic mammary implant as part of total pelvic exenteration for primary vaginal melanoma. 


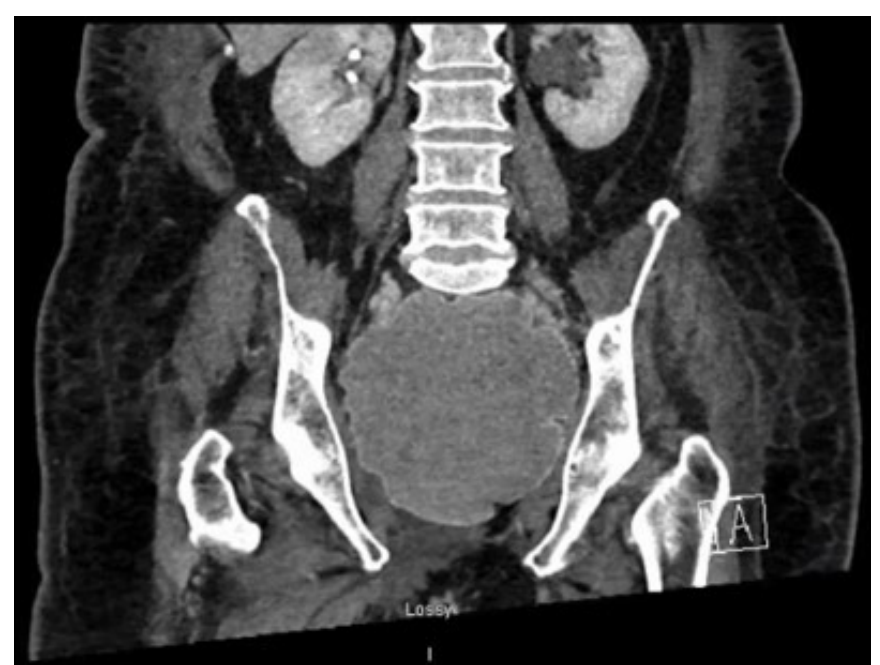

Figure 1 Post-operative radiology demonstrating satisfactory positioning of the mammary implant and significant reduction in pelvic dead space

the translocation of the small bowel into the pelvis, collectively termed 'empty pelvis syndrome'. ${ }^{1}$ Small case series have demonstrated decreased re-operation and long-term complication rates with mammary implants in rectal, ovarian, uterine, and cervical cancers. ${ }^{2}$ This is, to our knowledge, the first use of the technique in vaginal melanoma.

Contributors All authors made a substantial contribution to the conception and design of the video, and writing and editing of this original abstract. Each has contributed to drafting the video or revising it critically for important intellectual content, and has approved the final submitted video and abstract.

Funding The authors have not declared a specific grant for this research from any funding agency in the public, commercial, or not-for-profit sectors.

Competing interests None declared.

Patient consent for publication Not required.

Provenance and peer review Not commissioned; externally peer reviewed.

Data availability statement There are no data in this work.

ORCID iD

Robert Adam Farrell http://orcid.org/0000-0002-8459-1316

\section{REFERENCES}

1 Young JM, Badgery-Parker T, Masya LM, et al. Quality of life and other patient-reported outcomes following exenteration for pelvic malignancy. Br J Surg 2014;101:277-87.

2 Valle M, Federici O, lalongo $\mathrm{P}$, et al. Prevention of complications following pelvic exenteration with the use of mammary implants in the pelvic cavity: technique and results of 28 cases. J Surg Oncol 2011;103:34-8. 